\title{
Measuring disadvantage: changes in the underprivileged area, Townsend, and Carstairs scores 1981-91
}

\author{
Susan A Dolan, Brian Jarman, Madhavi Bajekal, Pat M Davies, Debbie Hart
}

\begin{abstract}
Objective - To compare the intercensal change for each of the underprivileged area (UPA), Townsend, and Carstairs scores calculated from 1981 and 1991 census data.

Setting - England and Wales.

Methods - The method described enables comparison of change in composite scores such as the UPA, Townsend, and Carstairs scores which are derived from normalised variables. The national values of equivalent variables derived from the censuses are calculated and normalised on the same baseline of the 1981 electoral ward mean and SD values. The resultant change in composite scores for different censuses can then be compared directly.

Main outcome measure - Change in the composite score values for the 1991 census when compared with the 1981 census.

Results - For England and Wales, the UPA score increased by 5.62 units $(0.35$ of the SD) but the Townsend and Carstairs scores fell by 2.39 and 1.13 units respectively) 0.71 and 0.33 of the SDs). Conclusion - The Townsend and Carstairs scores are good measures of material deprivation and show a general improvement as such between 1981 and 1991. The UPA score, however, includes additional factors relating to family structure, social deprivation, and health need and shows a decline in the overall situation.
\end{abstract}

(f Epidemiol Comm Health 1955;49(Suppl 2):S30-S33)

Earlier work has shown that the underprivileged area (UPA, otherwise known as the Jarman 8), Townsend, and Carstairs scores are useful in the measurement of health status and material disadvantage because there is strong correlation between these composite scores and various measures of health and other disadvantage, for example standardised mortality ratios (SMRs) and proportions of permanently sick and unemployed. ${ }^{12}$ For this reason they are used by various health and local authorities as "deprivation scores", in order to assist in targeting particular areas for funding or health promotion. The scores themselves were also strongly correlated with one another in $1981,{ }^{2}$ since they all seemed to measure similar factors contributing to disadvantage. The object of the current paper is to detail derivation of equivalent scores from the 1981 and 1991 censuses and compare the intercensal change in the scores.

The UPA, Townsend, and Carstairs scores have been calculated previously by this department using the census ward level small area statistics for the 9265 wards existing in England and Wales on the day of the 1981 census (City of London district counting as one ward). The details of the component variables and development of the resulting scores have been documented elsewhere. ${ }^{3-5}$ All variables are defined as ward proportions of a relevant resident population except for three Townsend variables, in which the household is the unit used to construct the variable (proportion without a car, in overcrowded housing, and not in owner occupied housing). All three scores are calculated using summation of the normalised variables (using the $\mathrm{Z}$ score method) after any necessary transformation (see table for details). In addition, a variety of weights are applied to the individual UPA variable $\mathrm{Z}$ scores before summation. These weights were calculated from scores given to each variable in a survey of the workload of one in 10 randomly selected UK general practitioners. The Townsend and Carstairs variable $Z$ scores are arbitrarily assigned a weight of unity. The means and SDs used in calculating the $\mathrm{Z}$ scores and the weights applied to them to obtain the composite scores are shown in the table.

\section{Method}

The following paragraphs describe the derivation of equivalent national component variables and the calculation of comparable scores.

\section{VARIABLES}

It was desirable to extract counts, as defined in 1981, from the 1991 census and calculate scores based on the national (England and Wales) variable values for both censuses for comparison. There had been two types of census changes affecting this study - alteration of the popular base and redefinition of some of the table counts. ${ }^{67} \mathrm{~A}$ further problem discovered after the 1991 census is that of under enumeration. ${ }^{8}$

\section{POPULATION BASE}

Clearly all counts were potentially affected by alteration of the population base. This change meant that, compared with 1981, there were additional residents in wholly absent house- 
Variable and score changes for underprivileged area (UPA), Townsend, and Carstairs scores 1981-91

\begin{tabular}{|c|c|c|c|c|c|c|c|c|c|c|c|}
\hline \multicolumn{2}{|l|}{ UPA score } & Row & $\begin{array}{l}\text { Resident } \\
\text { pensioners } \\
\text { living alone }\end{array}$ & $\begin{array}{l}\text { Resident } \\
\text { children }<5\end{array}$ & $\begin{array}{l}\text { Residents in } \\
\text { households } \\
\text { headed by lone } \\
\text { parent }\end{array}$ & $\begin{array}{l}\text { Residents in } \\
\text { households } \\
\text { headed by } \\
\text { unskilled }\end{array}$ & Unemployed & $\begin{array}{l}\text { Residents } \\
\text { overcrowded }\end{array}$ & $\begin{array}{l}\text { Residents who } \\
\text { had moved } \\
\text { house }\end{array}$ & $\begin{array}{l}\text { Residents in } \\
\text { households } \\
\text { headed by new } \\
\text { commonwealth }\end{array}$ & Score \\
\hline 1981 data: & $\begin{array}{l}\text { Weight } \\
\text { Ward mean } \\
\text { Ward SD } \\
\text { National } \\
\text { percentage }\end{array}$ & $\begin{array}{l}\text { (a) } \\
\text { (b) } \\
\text { (c) } \\
\text { (d) }\end{array}$ & $\begin{array}{l}6 \cdot 62 \\
0 \cdot 225728 \\
0 \cdot 045696 \\
5 \cdot 24\end{array}$ & $\begin{array}{l}4 \cdot 64 \\
0 \cdot 242967 \\
0 \cdot 031915 \\
6 \cdot 07\end{array}$ & $\begin{array}{l}3 \cdot 01 \\
0 \cdot 130706 \\
0 \cdot 037076 \\
2 \cdot 14\end{array}$ & $\begin{array}{l}3 \cdot 74 \\
0 \cdot 180831 \\
0 \cdot 089112 \\
4 \cdot 51\end{array}$ & $\begin{array}{l}3 \cdot 34 \\
0 \cdot 287542 \\
0 \cdot 078384 \\
9 \cdot 58\end{array}$ & $\begin{array}{l}2 \cdot 88 \\
0 \cdot 230986 \\
0 \cdot 080915 \\
7 \cdot 13\end{array}$ & $\begin{array}{l}2 \cdot 68 \\
0 \cdot 306805 \\
0 \cdot 056707 \\
9 \cdot 44\end{array}$ & $\begin{array}{l}2 \cdot 5 \\
0 \cdot 129818 \\
0 \cdot 115579 \\
4 \cdot 52\end{array}$ & $\begin{array}{l}-\overline{0} \\
15.993571 \\
-\end{array}$ \\
\hline \multirow[t]{2}{*}{1991 data: } & $\begin{array}{l}\text { Contribution } \\
\text { National } \\
\text { percentage }\end{array}$ & $\begin{array}{l}\text { (e) } \\
\text { (f) }\end{array}$ & $\begin{array}{l}0 \cdot 76 \\
6 \cdot 08\end{array}$ & $\begin{array}{l}0 \cdot 87 \\
6 \cdot 73\end{array}$ & $\begin{array}{l}1 \cdot 31 \\
4 \cdot 10\end{array}$ & $\begin{array}{l}1 \cdot 39 \\
2 \cdot 81\end{array}$ & $\begin{array}{l}1 \cdot 16 \\
9 \cdot 17\end{array}$ & $\begin{array}{l}1 \cdot 40 \\
4 \cdot 56\end{array}$ & $\begin{array}{l}0 \cdot 26 \\
9 \cdot 69\end{array}$ & $\begin{array}{l}1 \cdot 83 \\
5 \cdot 24\end{array}$ & ${ }^{8 \cdot 97}$ \\
\hline & Contribution & (g) & $3 \cdot 39$ & $2 \cdot 83$ & 5.94 & -0.52 & $0 \cdot 86$ & -0.56 & $0 \cdot 46$ & $2 \cdot 19$ & $14 \cdot 59$ \\
\hline \multicolumn{12}{|c|}{$\begin{array}{l}e=\operatorname{ax}(((\operatorname{arcsine}(\text { sq } \operatorname{root}(d / 100))))-b) / c) \\
g=\operatorname{ax}(((\operatorname{arc} \sin e(\operatorname{sq} \operatorname{root}(f / 100)))-b) / c)\end{array}$} \\
\hline $\begin{array}{l}\text { Townsend } \\
\text { score }\end{array}$ & & & Row & Unemplc & yed & $\begin{array}{l}\text { Households } \\
\text { overcrowded }\end{array}$ & Househol & ds without a co & $\begin{array}{l}\text { Household } \\
\text { occupied }\end{array}$ & ds not owner & Score \\
\hline $\begin{array}{l}1981 \text { data: } \\
1991 \text { data: }\end{array}$ & $\begin{array}{l}\text { Weight } \\
\text { Ward mean } \\
\text { Ward SD } \\
\text { National perce } \\
\text { Contribution } \\
\text { National perce } \\
\text { Contribution }\end{array}$ & $\begin{array}{l}\text { ntage } \\
\text { ntage }\end{array}$ & $\begin{array}{l}\text { (h) } \\
(\mathrm{i}) \\
(\mathrm{j}) \\
(\mathrm{k}) \\
(\mathrm{l}) \\
(\mathrm{m}) \\
(\mathrm{n})\end{array}$ & $\begin{array}{l}1 \\
2 \cdot 17622 \\
0 \cdot 43954 \\
9 \cdot 84 \\
0 \cdot 47 \\
9 \cdot 39 \\
0 \cdot 37\end{array}$ & & $\begin{array}{l}1 \\
1 \cdot 219934 \\
0 \cdot 449573 \\
4 \cdot 78 \\
1 \cdot 19 \\
2 \cdot 09 \\
-0 \cdot 20\end{array}$ & $\begin{array}{c}1 \\
32 \cdot 6277 \\
15 \cdot 3202 \\
38 \cdot 54 \\
0 \cdot 39 \\
32 \cdot 41 \\
-0 \cdot 01\end{array}$ & & $\begin{array}{c}1 \\
40 \cdot 02285 \\
19 \cdot 32850 \\
42 \cdot 24 \\
0 \cdot 11 \\
32 \cdot 54 \\
-0 \cdot 39\end{array}$ & & $\begin{array}{l}\overline{0} \\
3 \cdot 386369 \\
\overline{2} \cdot 16 \\
-0.23\end{array}$ \\
\hline
\end{tabular}

For unemployed, households overcrowded: $1=h x((($ natural logarithm $(k+1))-i) / j)$

For households without car, not owner-occupied: $l=h x((k-i) / j)$

For unemployed, households overcrowded: $n=h x((($ natural logarithm $(m+1))-i) / j)$

For households without car, not owner-occupied: $n=h x((m-i) / j)$

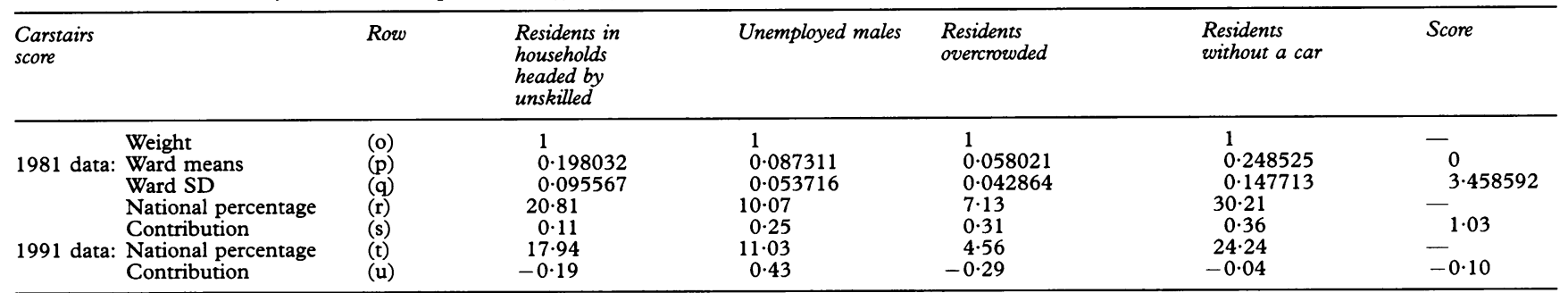

$\mathrm{s}=\mathrm{ox}((\mathrm{r}-\mathrm{p}) / \mathrm{q})$

$\mathrm{u}=\mathrm{ox}((\mathrm{t}-\mathrm{p}) / \mathrm{q})$

holds who returned forms after the census in time for processing and imputed residents for non-responding households. Residents in communal establishments were unaltered. The imputation of residents, however, gave rise to concern. The method used by the Office of Population Censuses and Surveys (OPCS) involves copying data from households absent on census night who subsequently returned a form in time for processing after matching with nonresponding households for basic household characteristics - this involves estimation, and thereby a degree of inaccuracy. Imputation affects both numerator and denominator counts and it is difficult to determine whether there is a bias from information currently available. At ward level the proportion of residents resulting from imputation varied widely - between 0 and $23 \%$. The wards with the highest proportion of imputed residents are in some of the inner London boroughs, eg Kensington and Chelsea, City of Westminster, Lambeth, and Brent. The imputation level for England and Wales as a whole, however, was $1 \cdot 6 \%$, and this is only slightly lower than the percentage of absent residents revealed by the census validation survey (estimated at $2 \cdot 1 \%$ ). ${ }^{9}$

\section{TABLE COUNT REDEFINITION}

Residents' social class/socioeconomic group

The coding of occupations was changed from the Classification of occupations (1980) to the Standard occupational classification (1990-91). ${ }^{7}$
This affected counts for derivation of the proportions of residents in households headed by an unskilled person, used in calculation of the UPA and Carstairs scores. The OPCS has shown that, in general, the discontinuity between the two classifications affects approximately $2 \%$ of occupations, ${ }^{10}$ half of which is due to domestic workers and cleaners being transferred from social class IV to social class V. Therefore this change will have little impact on the differences between the variable values in 1991 when compared with 1981.

\section{Residents' economic position}

Reclassification of students affected the counts for derivation of the proportions of unemployed, used in the calculation of all three scores. In 1991 students were classified as economically active if working or seeking work in the week before the census; in 1981 all students were classified as economically inactive. The effect of this was compounded by the fact that the 1991 census was held on 21st April which was during term-time for some colleges but not for others. In England and Wales 12\% of students were recorded as economically active at the 1991 census but students as a whole comprised only $4 \%$ of the resident population aged 16 years and over. Therefore this change is unlikely to have much affect on the differences seen between the 1981 and the 1991 values of variables used to measure unemployment. 


\section{Household overcrowding}

The counts for the proportion of overcrowded residents or households used in all three scores were affected to varying degrees by the reclassification of offices and shops used solely for business. In 1991 these rooms were included if they were an integral part of the accommodation - in 1981 they were excluded. It is not certain what difference, if any, this change in definition will have, but it is likely to be small.

Therefore a minority of the UPA variables have been affected by redefinition of table counts, but two of the Townsend and three of the Carstairs variables are thus affected. It is not anticipated that any of these changes will be substantive.

\section{UNDER ENUMERATION}

The OPCS conducts a census validation survey within a few weeks of each census in order to estimate the accuracy of census data. ${ }^{9}$ This survey showed that there were two sources of error in the counts: under enumeration (due to households missed by the enumerator or people not being included on census forms) and over imputation (by the OPCS of people in "absent" households not returning a census form in time for processing). This showed that $0.5 \%$ or 250000 net (approximately) residents were missing from the census figures. In addition, on comparing the adjusted census counts to the 1981 based, rolled forward population estimates (which are considered to be accurate), it was discovered that there was a further shortfall of nearly 1 million residents not detected by the census validation survey. The sex and age of people recorded in vital statistics are known and therefore the OPCS has been able to produce overall adjustment factors for both sexes in five year age bands. ${ }^{8} \mathrm{It}$ has also been able to produce correction factors which may be used for dwelling type and numbers of residents in relation to the ethnic group or very broad geographical location (inner and outer London, metropolitan areas, cities, and non-metropolitan areas in general). The relevant counts for which published adjustment factors could reasonably be used were those of children under 5 years and persons of pensionable age (variables which are used in construction of the UPA score). The values of the factors were low (on average about 1.02) and, if used, would have had little effect on the resultant component variables. Therefore it was decided not to use them in this study.

\section{CALCULATION}

The method used by this department for calculation of the 1991 based scores was identical to that used for the 1981 scores. In effect, the same transformations were applied to the census derived national variables and the same weights were used for the normalised transformed values ( $Z$ scores). The 1981 ward means and SDs of the transformed variables were used in all calculations of $Z$ scores, which meant that the value obtained for a score from the 1991 data could be directly compared with that for 1981. The means and SDs used are shown in the table.

\section{Results}

The table shows that between 1981 and 1991 the national percentage values of five of the UPA score variables increased (three decreased) and all but one of the Townsend and Carstairs scores' values decreased (the exception being a small increase in the Carstairs score of the percentage unemployed). The contribution of each variable to the composite scores is shown for each census. These values are the weighted, normalised, transformed national values. The composite scores obtained from the addition of these values are also shown. There has been a national increase of 5.62 units in the UPA score for the period 1981-91 and national decreases of 2.39 and $1 \cdot 13$ units for Townsend and Carstairs scores respectively. This department has calculated the UPA, Townsend, and Carstairs scores from the 1991 census data reaggregated into 1981 ward boundaries and has found that the ward SDs are similar, and therefore it was reasonable to use the 1981 SDs for the two censuses when quantifying the intercensal changes in terms of wards. The SDs are $+0.35,-0.71$, and -0.33 for the UPA, Townsend, and Carstairs scores respectively.

\section{Discussion}

In the context of quantifying change, it is appropriate to consider first the robustness of the scores in general. All three scores are composite, which will tend to increase their robustness as such. The nature of some of the variables, such as demographic proportions, will tend to robustness as these are not easily alterable by economic policy: these variable include resident pensioners living alone, children under 5, residents in households headed by unskilled people and headed by people from the new commonwealth. Among these variables, those which could be expected to increase monotonely are resident pensioners living alone and residents in households headed by someone from the new commonwealth: one could reasonably expect residents in households headed by the unskilled to decrease monotonely. The variables which may lead to scores that are not particularly robust, as their values may show more erratic year-on-year change (depending on circumstances) are: unemployed and residents who had moved house.

It has been shown for 1981 that these three scores showed approximately the same areas to be disadvantaged and this effect remained when other scores were considered in addition. We have been able to quantify the consistency over time for each score by examining the values obtained for the 1981 and 1991 censuses, and additionally the 1971 census for the UPA score. The comparison has been done at local authority level because ward level data were not made available for 1971 . Use was made of the 1971-81 change file made available by the 
OPCS specifically for comparison of 1971 and 1981 censuses. It was possible to derive a UPA score from five of the eight variables (see below). For the purposes of the 1971-81 comparison, a 1981 score was derived in the same way. The 1981-91 comparison is based on the full eight variable scores. The consistency was assessed in terms of the Spearman rank correlation coefficient and the results were as follows (coefficients 1971-81 and 1981-91 in brackets): UPA score $(0.89,0.93)$ Townsend (N/A, 0.96), and Carstairs (N/A, 0.97). The five UPA variables for which it was possible, from the tables supplied, to quantify change for 1971-81 were as follows (change 1971-81 in brackets): resident pensioners living alone $(+27 \%)$, children under $5(-26 \%)$, unemployed $(+86 \%)$, residents overcrowded $(-45 \%)$, and residents in households headed by someone from the new commonwealth $(+38 \%)$. These results support the remarks made on the relative stability of demographic proportions compared with other variables that are more easily affected by economic circumstance. The results displayed in the table show change in the relevant variables for 1981-91 and are now discussed for each score.

\section{UPA SCORE}

The largest increase in the intercensal decade occurred in the proportion of residents in households headed by a lone parent - this has nearly doubled. This is confirmed by the fact that the contribution of this variable to the score is nearly fivefold when compared with 1981. Large increases have also occurred in the proportions of resident children aged under 5 years and lone pensioners, whose contributions to the score have increased by threefold and fourfold respectively. The two variables with notable decreases are proportions of residents in overcrowded households and in households headed by an unskilled person (down by $36 \%$ and $38 \%$ respectively). Their contribution to the score has become negative when compared with 1981 .

TOWNSEND SCORE

The values of all the Townsend proportions have fallen, especially overcrowded households and households that are not owner occupied (down by approximately $56 \%$ and $23 \%$ respectively). For this reason the contribution to the score of three of the variables has become negative.

\section{CARSTAIRS SCORE}

The values of all the Carstairs proportions have fallen, save the number of men seeking work. The largest fall, as with the other composite scores, has been in the proportions of residents in overcrowded households ( $36 \%$ reduction).

\section{Conclusion}

We have presented a methodology which may be used for comparing intercensal changes for any composite scores calculated from values derived from normalised $(Z)$ scores. Our results show that the UPA, Townsend, and Carstairs scores measure different components of health disadvantage. Townsend and Carstairs scores mainly measure material deprivation factors and it is clear that these show a net improvement, in accordance with the overall increase in disposable incomes in real terms (although with wider differentials). ${ }^{11}$ The composition of the UPA score has, in addition to material deprivation factors, elements relating to family structure, social deprivation, and health need. This score shows a general worsening in the overall absolute values of these factors which outweigh the improvement in material deprivation factors.

1 Campbell D, Radford J, Burton P. Unemployment rates: an alternative to the Jarman index? $B M \mathcal{F} 1991 ; 303: 750-5$ 2 Morris R, Carstairs V. Which deprivation? A comparison of selected deprivation indices. $\mathscr{f}$ Public Health Med 1991, 13:318-26.

3 Jarman B. Identification of underprivileged areas. BMF 1983;286:1705-9.

4 Townsend P, Phillimore P, Beattie A. Health and deprivation. Inequality and the north. London: Croon Helm; 1988.

5 Carstairs V, Morris R. Deprivation and health in Scotland. Aberdeen: Aberdeen University Press; 1991.

6 Dale A, Marsh C, eds. The 1991 census user's guide. London: HMSO, 1993 .

7 Office of Population Censuses and Surveys/General Registrar's Office. 1991 census. Definitions. London: HMSO, gistrar's 1992 .

8 Office of Population Censuses and Surveys/General Registrar's Office. 1991 census user guide 58. London: OPCS 1994.

9 Office of Population Censuses and Surveys. 1991 censu validation survey coverage report. London: HMSO, 1994.

10 Office of Population Censuses and Surveys and Employmen Department Group. The standard occupational classification, Vol 3: Social classification and coding methodology. London HMSO, 1991.

11 Central Statistical Office. Social trends 23. London: HMSO 1993.

\section{Open discussion}

BEN SHLOMO - There has been some debate about which indices should be used. Although all of them have very high correlations, additional remuneration is only given to the extreme, the most deprived general practices, and there are differences in the classification. If you look at the changes between 1981-91, did the situation become even more divergent or not?

JARMAN - The shape of the curve has changed and if you use the 1981 means and SDs - that is, standardise in the same way, there is actually a slightly higher proportion of people currently deprived. In fact the distribution of deprivation is wider, there are more rich people and more poor people so more people are included in the deprived areas. The cut off point for payments to practices in deprived areas is much too high. We sent out other questionnaires to GPs saying, "Are you in a deprived area?" and more than $50 \%$ said "yes" at a cut off point of 10 , which is about half of an SD. The Department of Health actually pay at two SDs, however. There is also the problem of enumeration districts, wards, and postcodes. In Scotland they have used postcodes, in England and Wales wards. The postcodes are less numerically accurate but more geographically accurate. The general impression talking to GPs is that they do not really care enormously about the numerical precision but prefer geographical precision - it seems more accurate - and a postcode can be correctly located. One of the problems, however, is the boundary changes that occurred between the censuses. 